\title{
A DENUDER-FILTER SAMPLING TECHNIQUE FOR THE DETECTION OF GAS AND PARTICLE PHASE CARBONYL COMPOUNDS
}

Brice Temime ${ }^{\dagger}$, Robert M. Healy and John C. Wenger*, Department of Chemistry and Environmental Research Institute, University College Cork, Cork, Ireland.

${ }^{\dagger}$ Present address: Laboratoire Chimie et Environnement, Université de Provence, Marseille, France 


\section{Denuder Collection Efficiency}

Results from the collection efficiency tests for the 5 groups of carbonyl compounds are shown in Figures S1-S5. To ensure the accuracy and reproducibility of the experimental collection efficiency results, the analytical methods were first validated in terms of precision and blank. In order to remove any contaminants, all glass apparatus was soaked in deionised water and placed in a sonication bath for 60 minutes, then carefully rinsed with methanol and dichloromethane. Blank samples of the impingers and gas syringe were carried out at regular intervals in the same manner as the real samples. Although very low background values were observed for a few of the target compounds, the size of the signals were less than the uncertainty associated with their measurement (see Table ST1). The precision of the analytical method was calculated by taking 5 replicate samples from the chamber (i.e. sampling port before the entrance of the denuder tube) using both the gas-tight syringe and PFBHA impingers. The reproducibility, in terms of the relative standard deviation, is shown in Table ST1. The relative standard deviation ranged from 3 to $21 \%$ depending on the compound and the sampling method. Both methods provide a satisfactory level of precision as the values take into account; (i) variability in the manual syringe sampling at the inlet of the denuder tube, manual injection and GC-MS analysis for the gastight syringe; (ii) variability in the sampling, derivatization, extraction, filtration and GC-MS analysis with the PFBHA impinger. 

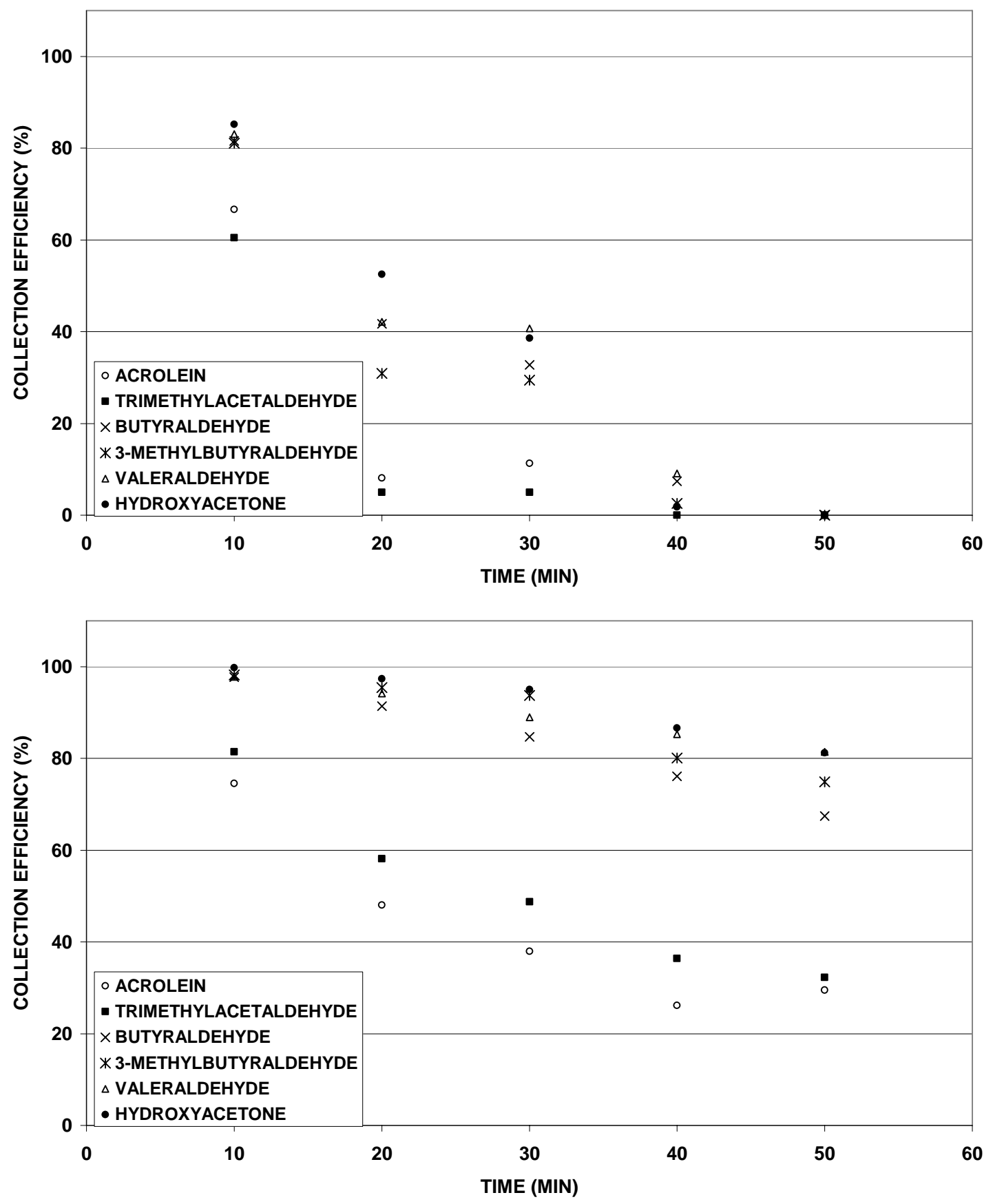

Figure S1. Collection efficiency of carbonyls for a denuder coated with XAD-4 (top) and XAD-4+PFBHA (bottom). 

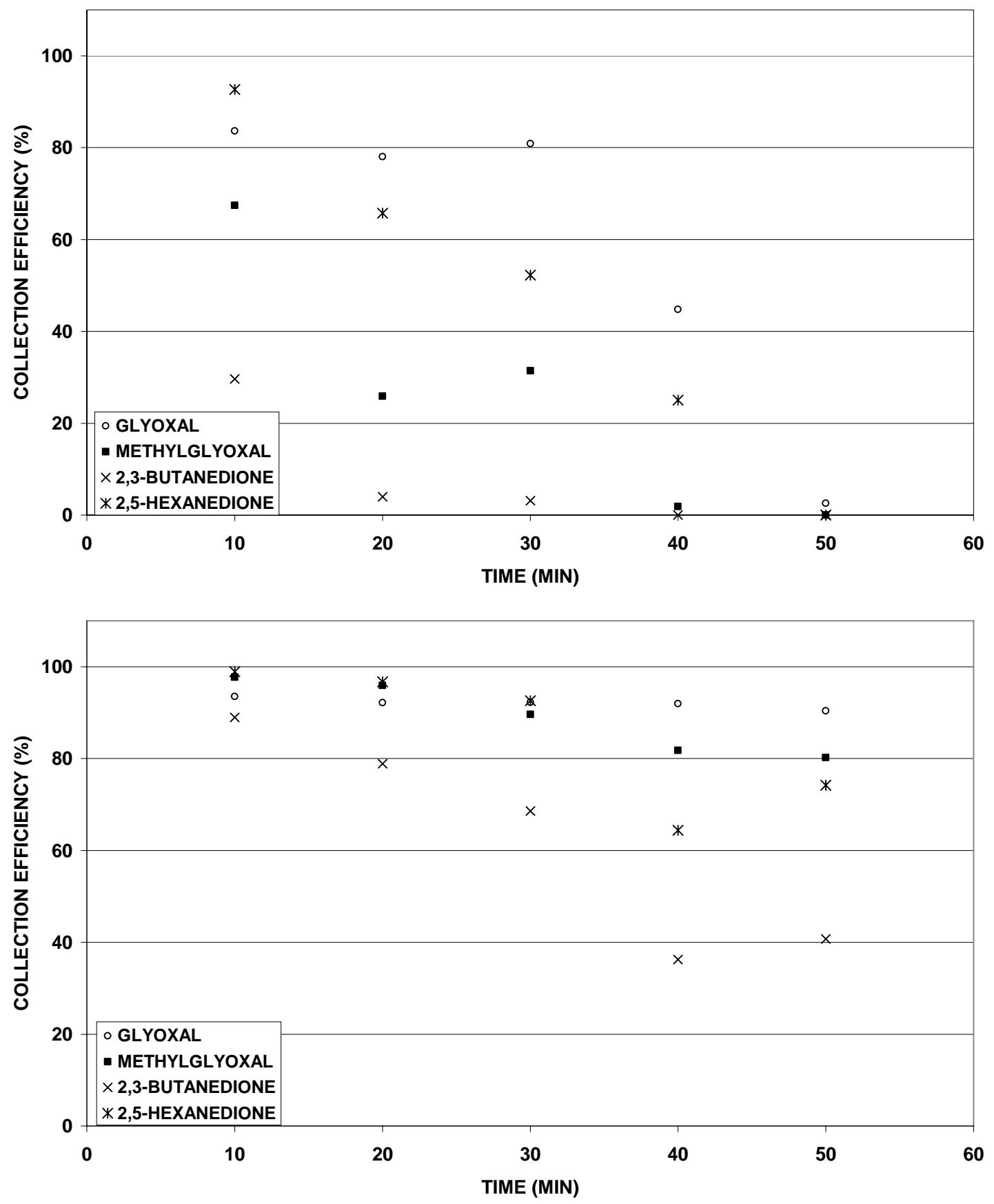

Figure S2. Collection efficiency of dicarbonyls for a denuder coated with XAD-4 (top) and XAD-4+PFBHA (bottom.) 

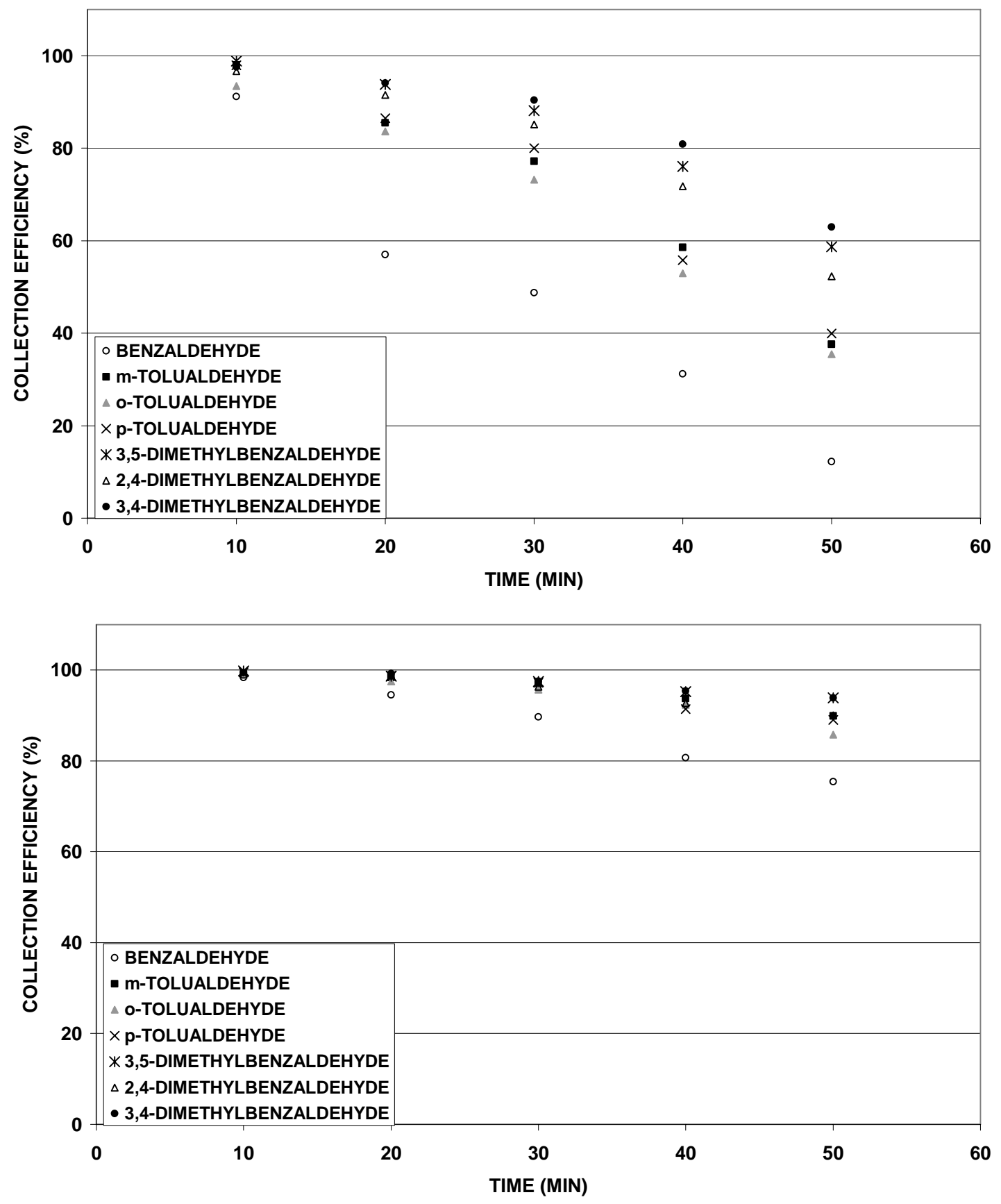

Figure S3. Collection efficiency of aromatic aldehydes for a denuder coated with $X A D-4$ (top) and XAD-4+PFBHA (bottom). 

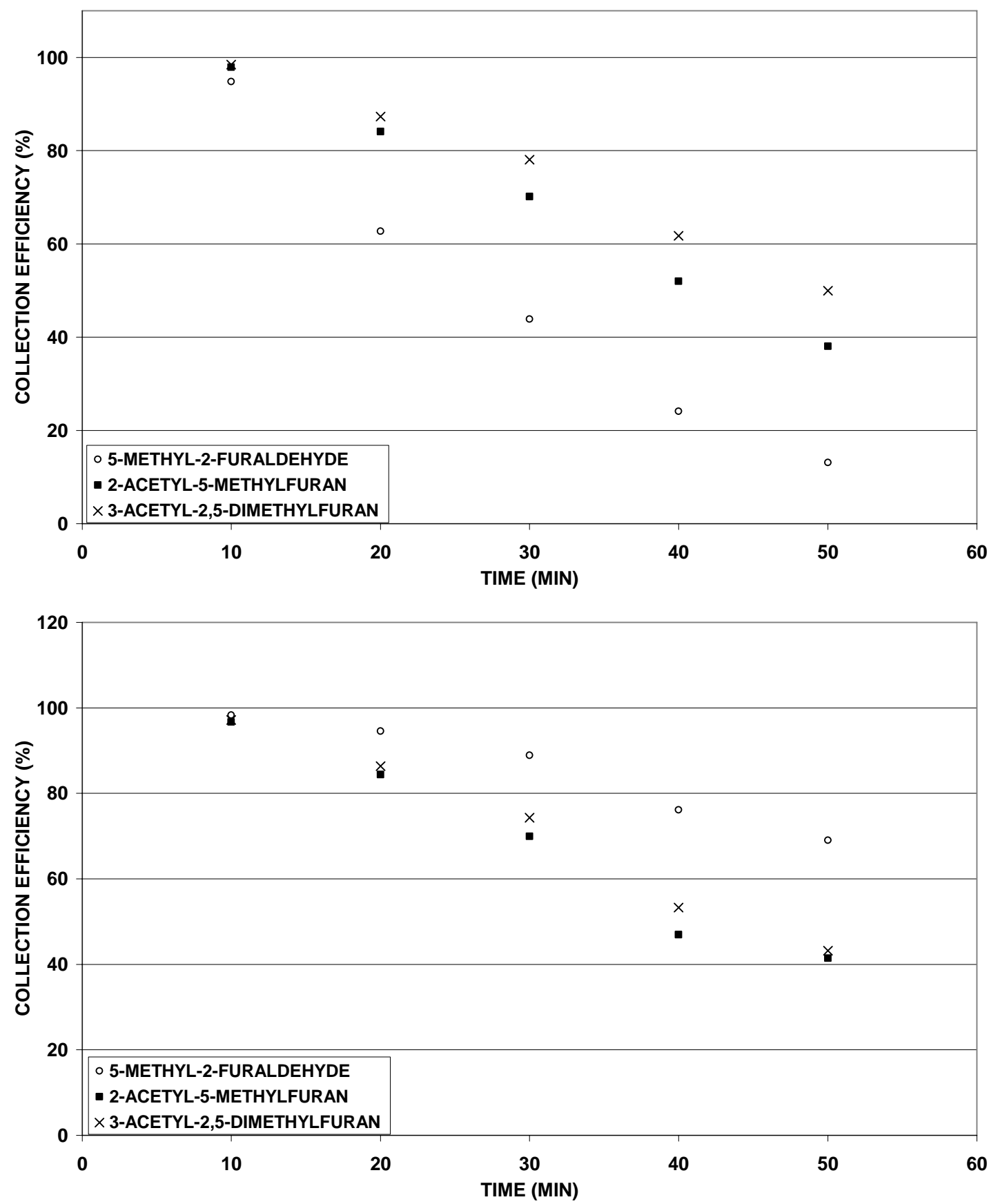

Figure S4. Collection efficiency of carbonyl-containing furans for a denuder coated with XAD-4 (top) and XAD-4+PFBHA (bottom). 

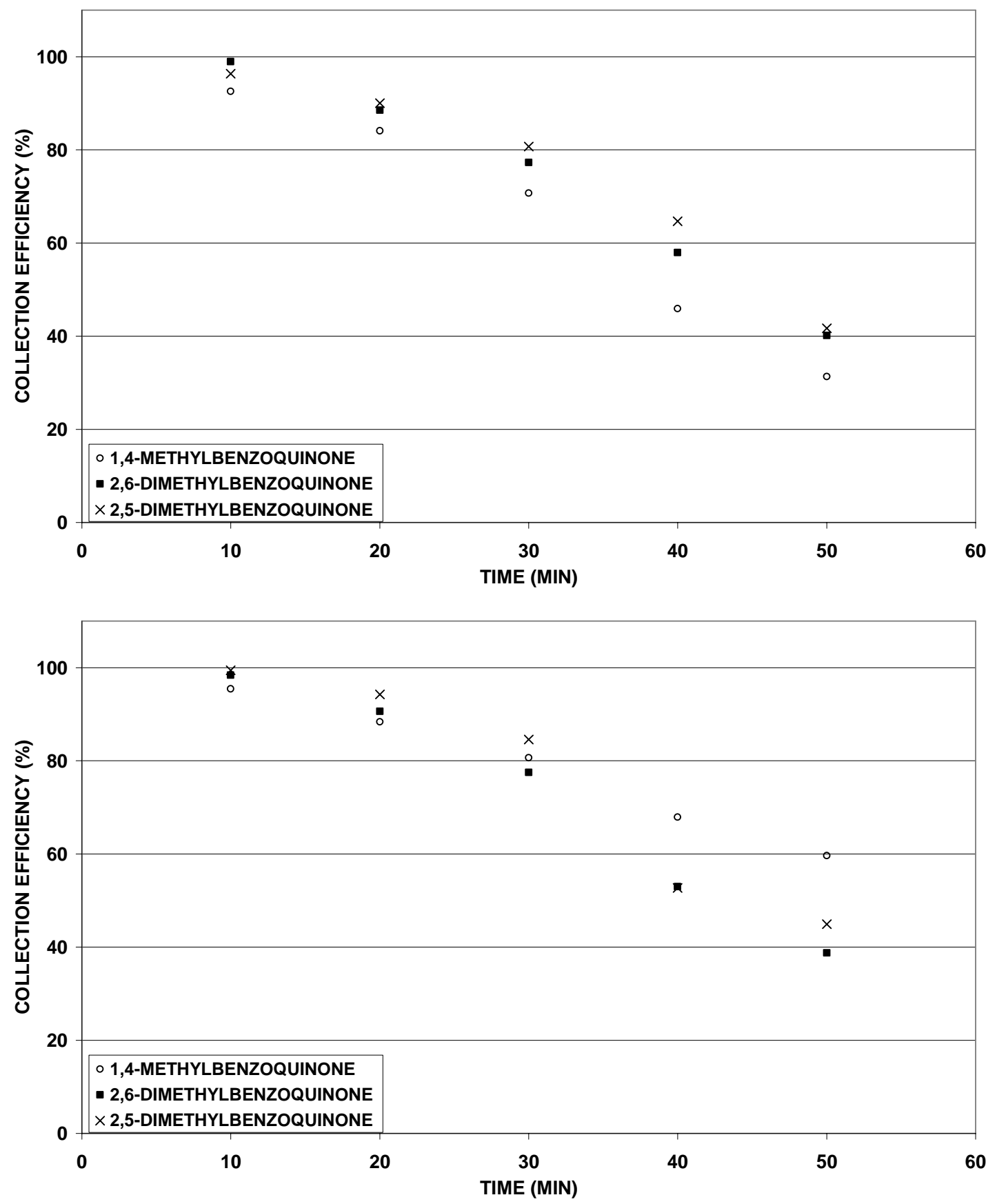

Figure S5. Collection efficiency of benzoquinones for a denuder coated with XAD-4 (top) and XAD-4+PFBHA (bottom). 


\begin{tabular}{|c|c|c|}
\hline Compound & Gas-tight syringe & PFBHA Impinger \\
\hline Acrolein & n.d & 9.9 \\
\hline Trimetylacetaldehyde & n.d & 9.4 \\
\hline Butyraldehyde & n.d & 6.9 \\
\hline 3-methylbutyraldehyde & n.d & 5.1 \\
\hline Valeraldehyde & n.d & 3.7 \\
\hline Hydroxyacetone & n.d & 12.1 \\
\hline Glyoxal & n.d & 14.3 \\
\hline Methylglyoxal & n.d & 12.6 \\
\hline 2,3-butanedione & n.d & 15.3 \\
\hline 2,5-hexanedione & n.d & 16.3 \\
\hline Benzaldehyde & 4 & 11.5 \\
\hline m,p-tolualdehyde & 7 & 12.8 \\
\hline o-tolualdehyde & 7 & 12.7 \\
\hline 3,5-dimethylbenzaldehyde & 12 & 18.1 \\
\hline 2,4-dimethylbenzaldehyde & 19 & 13.0 \\
\hline 3,4-dimethylbenzaldehyde & 11 & 20.9 \\
\hline 5-methyl-2-Furaldehyde & 3 & 8.2 \\
\hline 2-acetyl-5-methylfuran & 3 & 9.9 \\
\hline 3-acetyl-2,5-dimethylfuran & 13 & 14.8 \\
\hline 1,4-methylbenzoquinone & 14 & 8.7 \\
\hline 2,5-dimethylbenzoquinone & 9 & 17.1 \\
\hline 2,6-dimethylbenzoquinone & 17 & 11.3 \\
\hline
\end{tabular}

Table ST1. Relative standard deviations (\%) obtained ( $n=5)$ for GC-MS injections during collection efficiency tests (n.d. = not determined). 


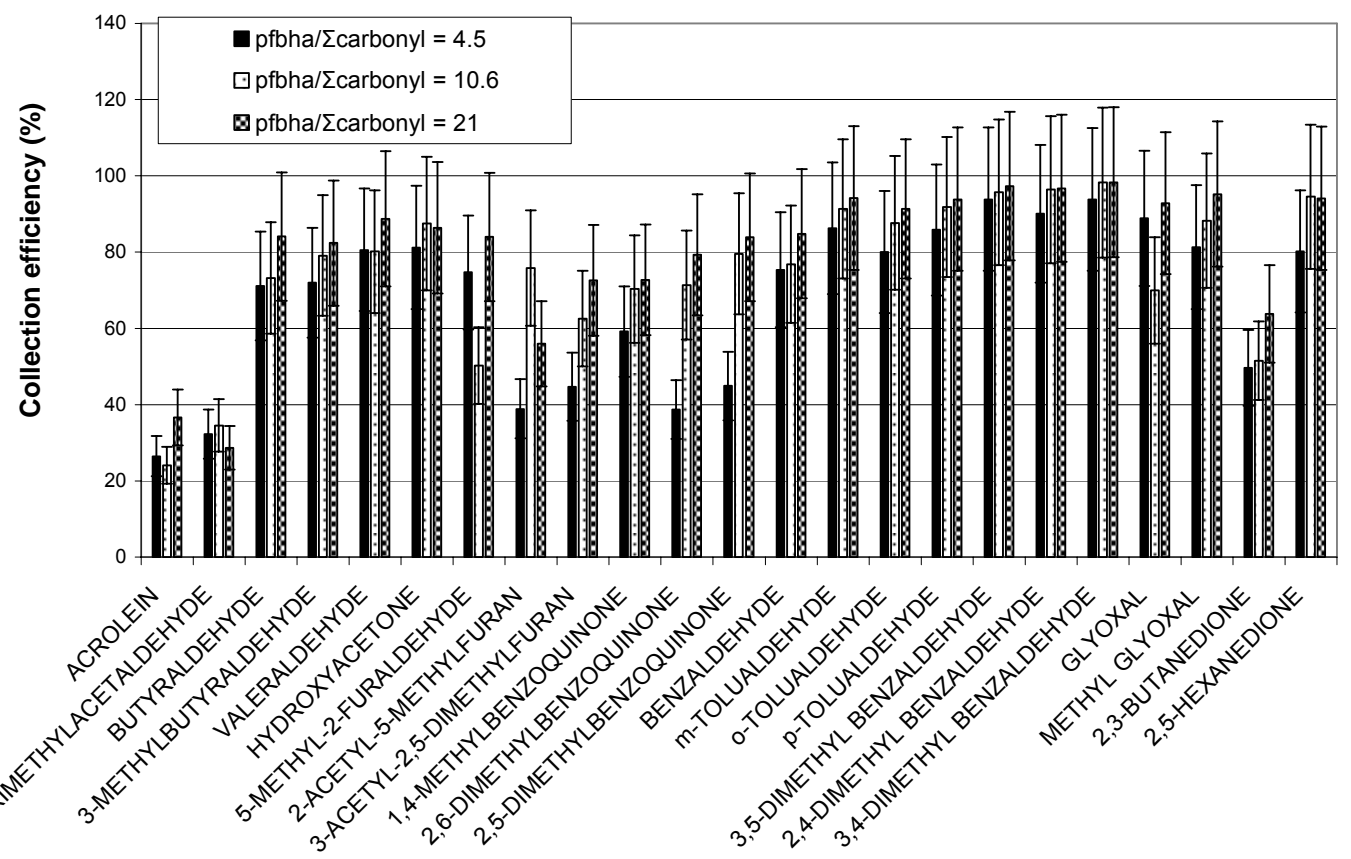

Figure S6. Effect of PFBHA loading on collection efficiency (sampling time $40 \mathrm{~min}$ at $20 \mathrm{~L} \mathrm{~min}^{-1}$ ). 


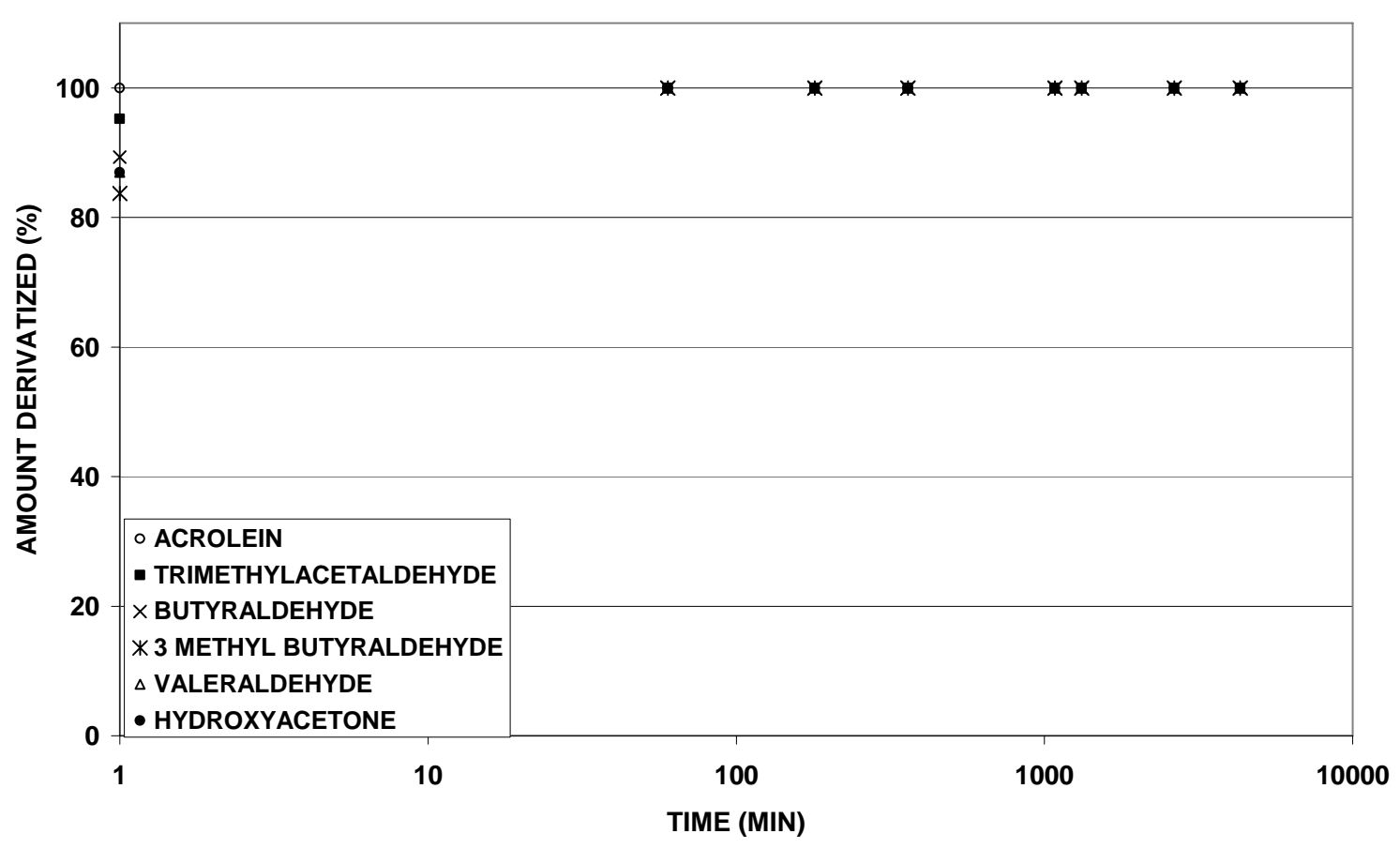

Figure S7. Advancement of the derivatization reaction as a function of the denuder storage time for small carbonyls. The extent of derivatization was calculated using the ratio of the peak height of the derivatized form to the sum of the peak heights for the derivatized and un-derivatized forms normalized to the GC-MS response factor. Response factors for the underivatized carbonyls were determined using a standard mixture analysed before and after derivatization. 


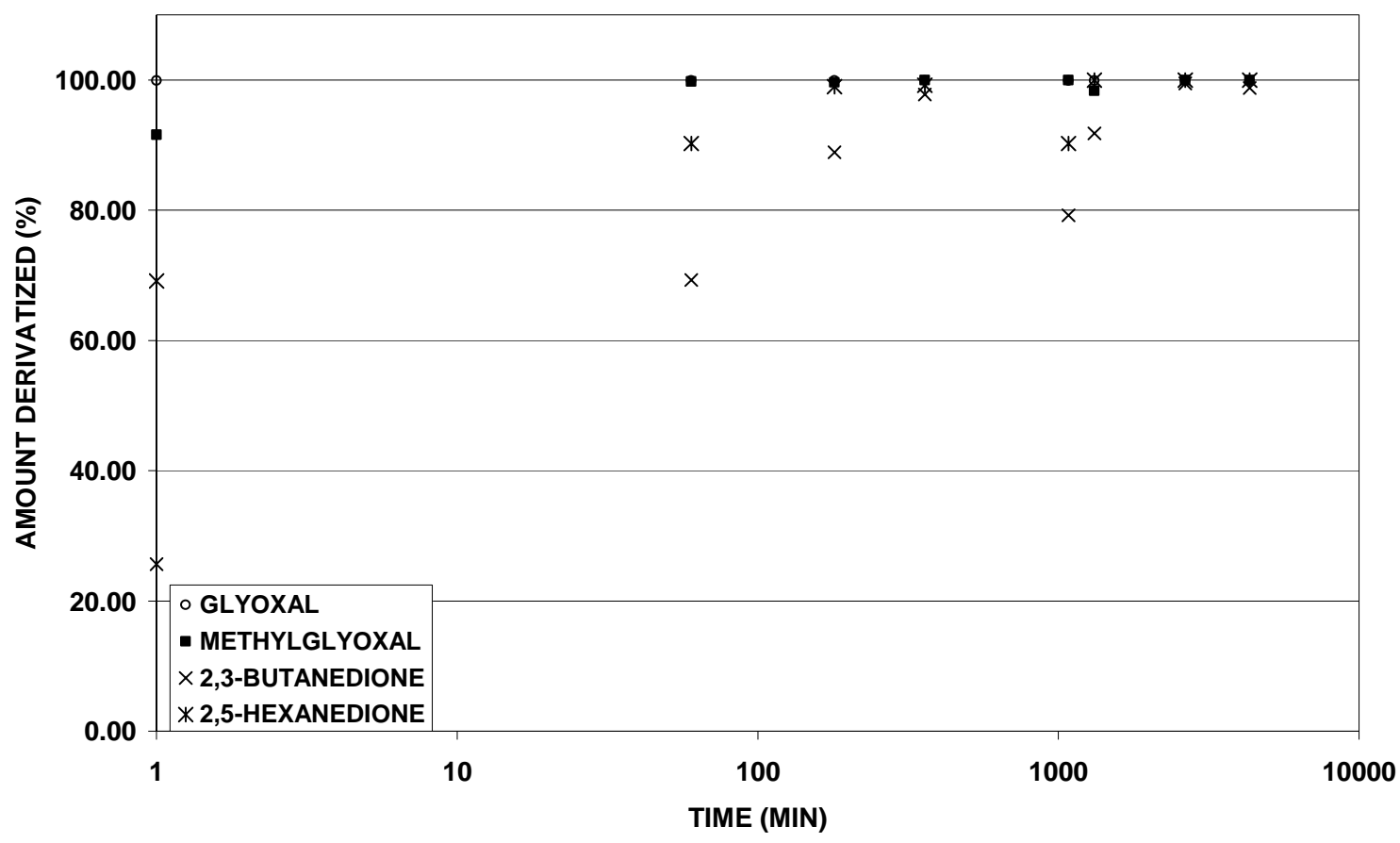

Figure S8. Advancement of the derivatization reaction as a function of the denuder storage time for dicarbonyls. The extent of derivatization was calculated using the ratio of the peak height of the di-derivatized form to the sum of the peak heights for the mono- and di-derivatized forms. 


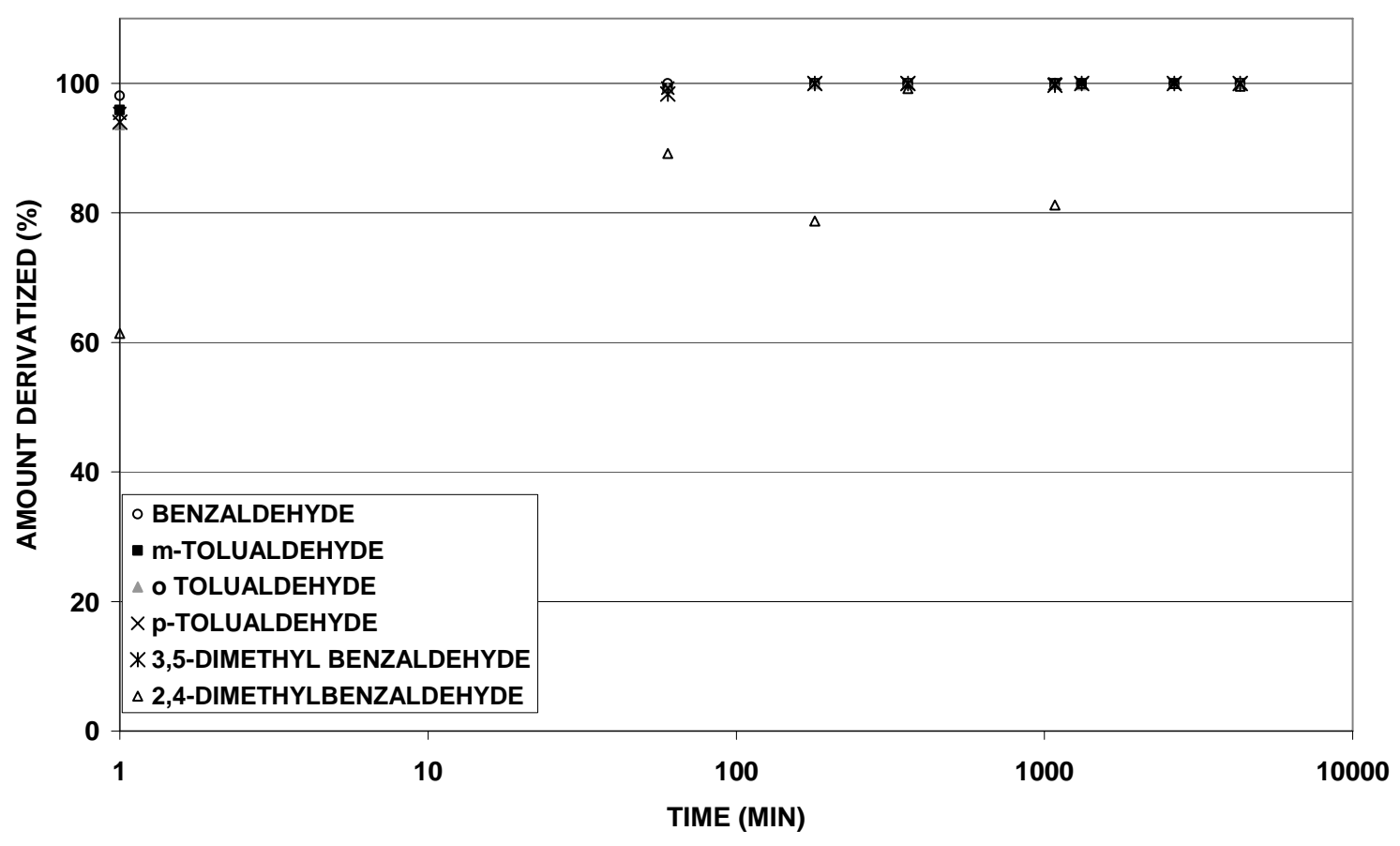

Figure S9. Advancement of the derivatization reaction as a function of the denuder storage time for aromatic aldehydes. The extent of derivatization was calculated using the ratio of the peak height of the derivatized form to the sum of the peak heights for the derivatized and un-derivatized forms normalized to the GC-MS response factor. Response factors for the underivatized carbonyls were determined using a standard mixture analysed before and after derivatization. 


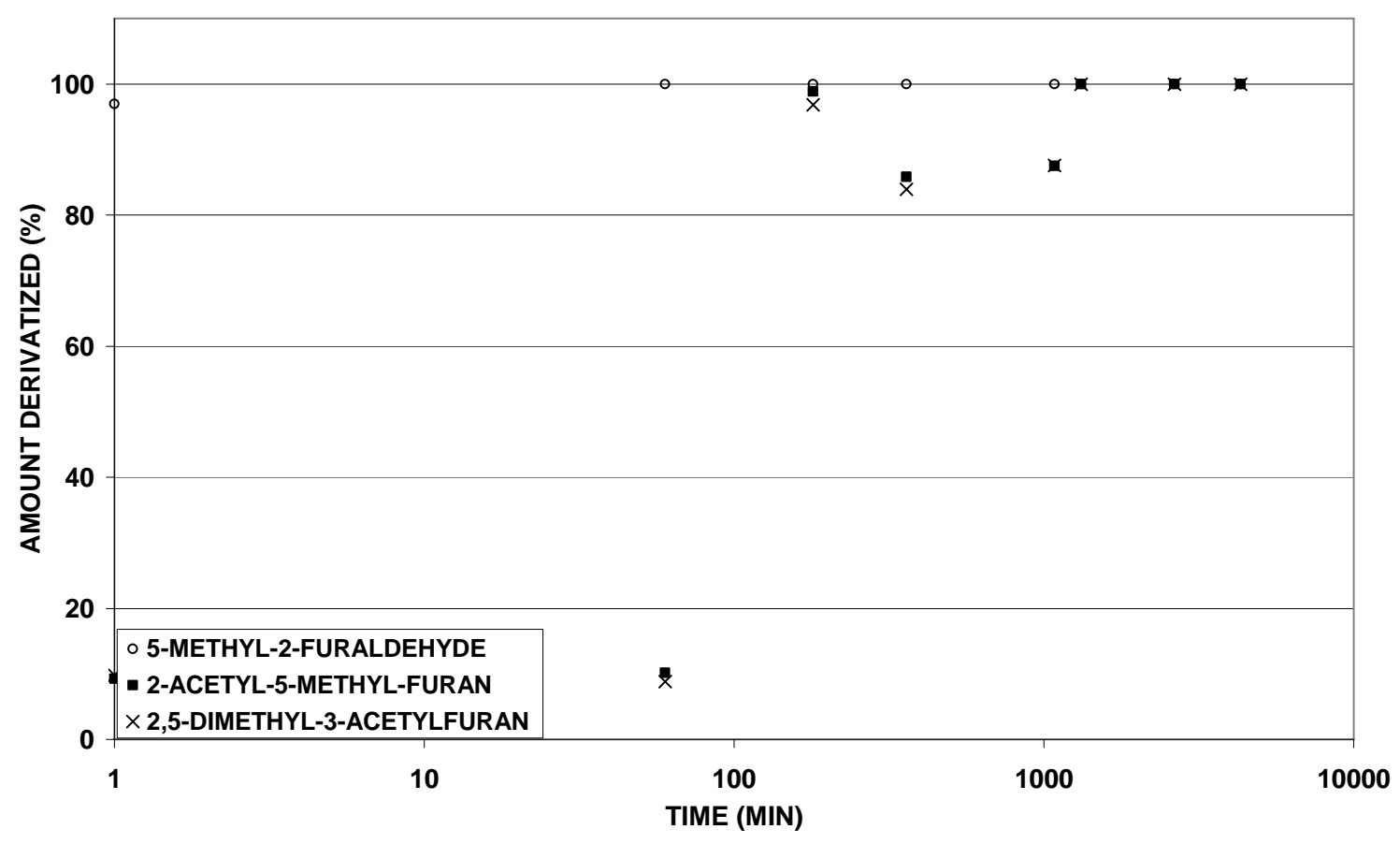

Figure S10. Advancement of the derivatization reaction as a function of the denuder storage time for carbonyl-containing furans. The extent of derivatization was calculated using the ratio of the peak height of the derivatized form to the sum of the peak heights for the derivatized and un-derivatized forms normalized to the GC-MS response factor. Response factors for the underivatized carbonyls were determined using a standard mixture analysed before and after derivatization. 


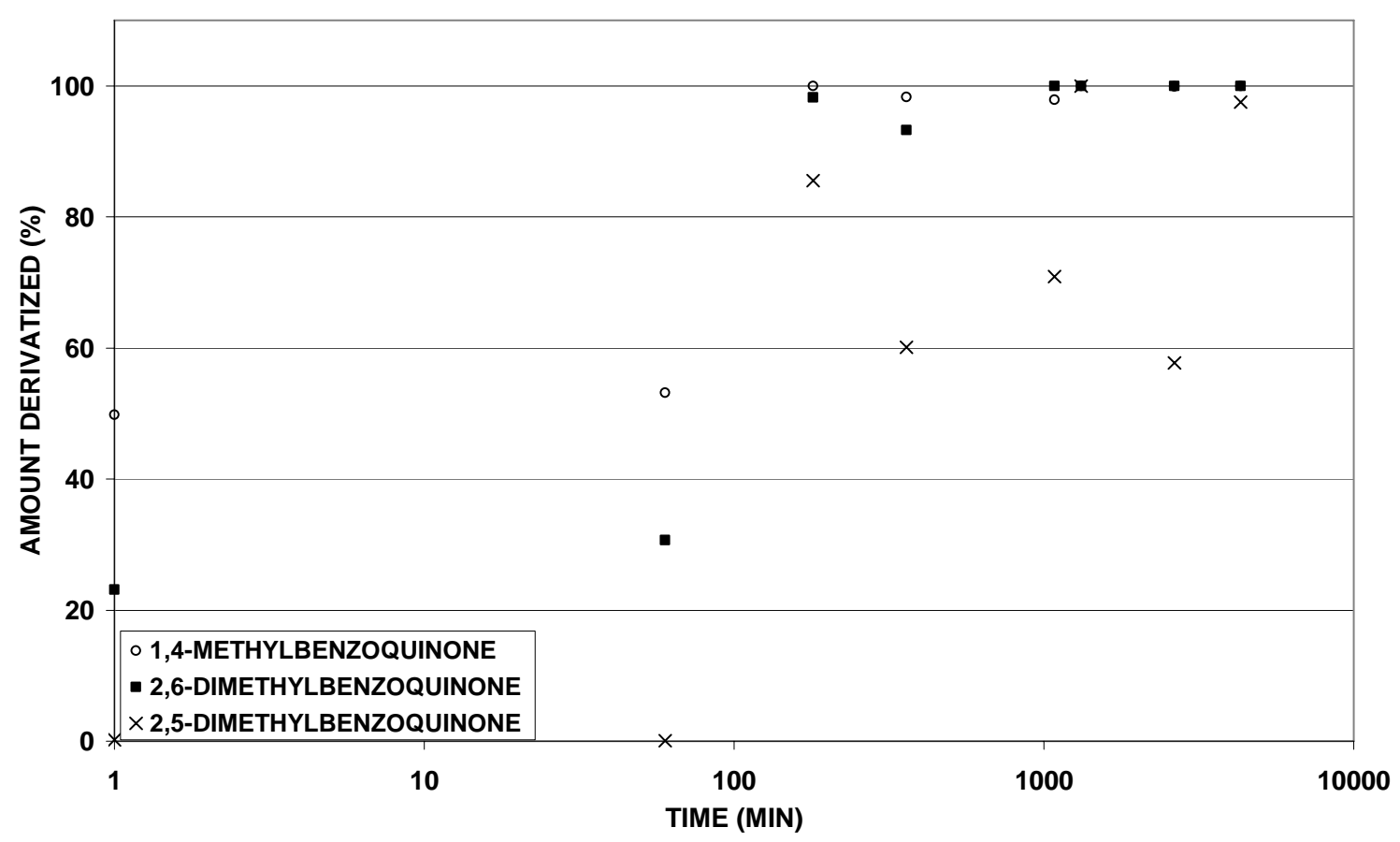

Figure S11. Advancement of the derivatization reaction as a function of the denuder storage time for benzoquinones. The extent of derivatization was calculated using the ratio of the peak height of the derivatized form to the sum of the peak heights for the derivatized and un-derivatized forms normalized to the GCMS response factor. Response factors for the underivatized carbonyls were determined using a standard mixture analysed before and after derivatization. 
Extraction of Derivatives from the Denuder

\begin{tabular}{|c|c|c|c|c|c|c|}
\hline & \multicolumn{3}{|c|}{ Storage period = 24 } & \multicolumn{3}{c|}{ Storage period = 48 } \\
& \multicolumn{3}{|c|}{ hours } & \multicolumn{3}{c|}{ hours } \\
\hline Compound & A & B & C & A & B & C \\
\hline Glyoxal & 100 & 100 & 100 & 100 & 100 & 100 \\
\hline Methylglyoxal & 100 & 100 & 100 & 100 & 100 & 100 \\
\hline 2,3-butanedione & 90.6 & 88.3 & 87.4 & 97.4 & 98.9 & 96.7 \\
\hline 2-acetyl-5-methylfuran & 100 & 100 & 100 & 100 & 100 & 100 \\
\hline 1,4-methylbenzoquinone & 100 & 100 & 94.6 & 100 & 100 & 100 \\
\hline 2,5-dimethylbenzoquinone & 84.6 & 94 & 87.9 & 94.4 & 98.8 & 96.2 \\
\hline
\end{tabular}

Table ST2. Derivatization yields obtained using three different extraction solvents; $\begin{array}{llllll}\text { (A) } \quad \text { methanol; } & \text { (B) } \text { water/acetonitrile } & (9.875 / 0.125 & v / v) ; & \text { (C) }\end{array}$ methanol/dichloromethane/acetonitrile (0.5/8.5/1 v/v/v). 


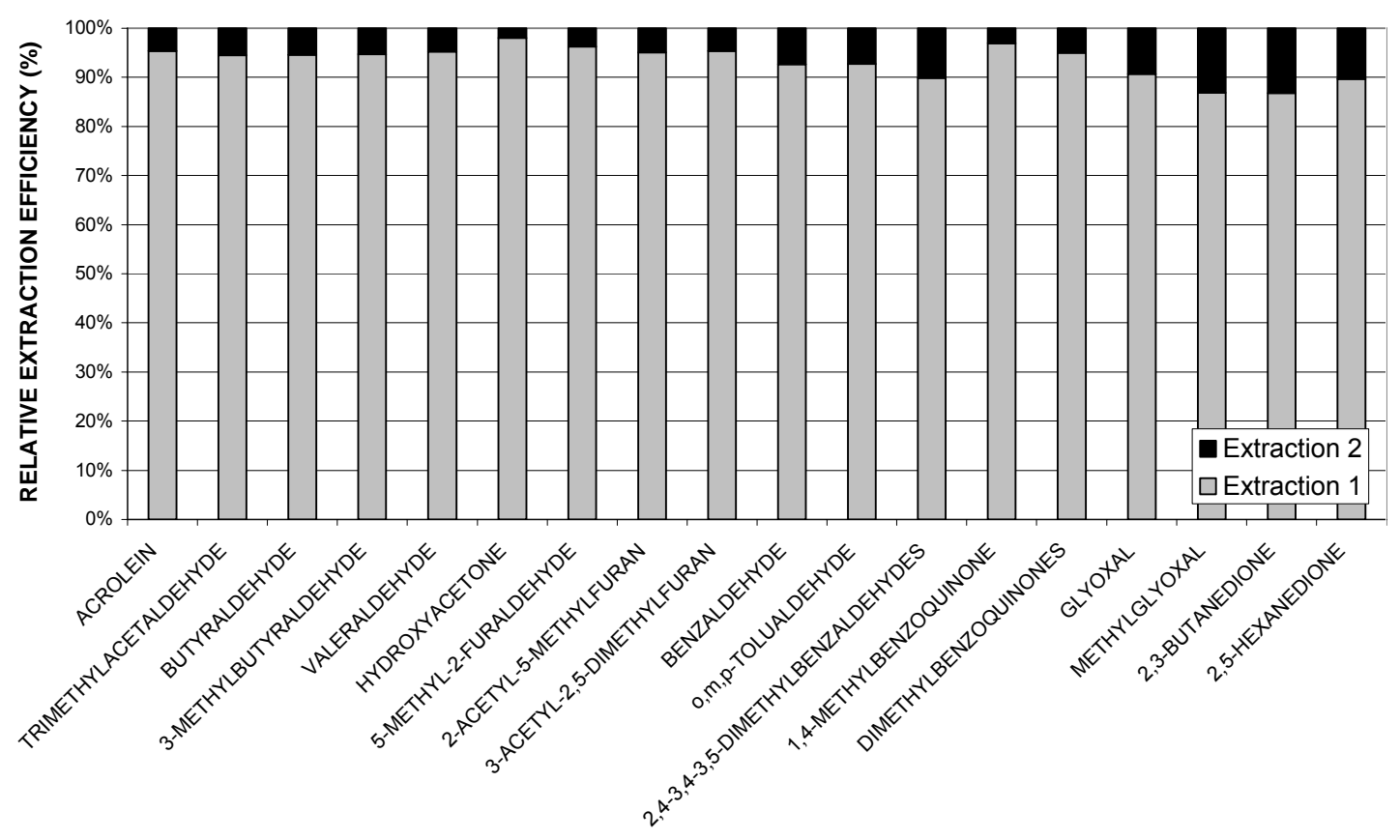

Figure S12. Recovery yields for derivatized carbonyls using two consecutive extractions with solvent mixture $C$. 


\begin{tabular}{|c|c|c|}
\hline Compound & Concentration (ppbV) & RSD (\%) \\
\hline Butyraldehyde & 66 & 3.5 \\
\hline 3-methylbutyraldehyde & 63 & 4.3 \\
\hline Valeraldehyde & 60 & 3.4 \\
\hline Hydroxyacetone & 77 & 9.2 \\
\hline Glyoxal & 226 & 2.2 \\
\hline Methylglyoxal & 134 & 4.8 \\
\hline 2,3-butanedione & 91 & 5.8 \\
\hline Benzaldehyde & 38 & 5.1 \\
\hline p-tolualdehyde & 54 & 7.0 \\
\hline 3,5-dimethylbenzaldehyde & 30 & 7.9 \\
\hline 5-methyl-2-furaldehyde & 36 & 5.4 \\
\hline 2-acetyl-5-methylfuran & 62 & 12.2 \\
\hline 2,5-dimethylbenzoquinone & 35 & \\
\hline
\end{tabular}

Table ST3. Relative standard deviations $(n=4)$ of the MS signal obtained from analysis of extracts during the denuder reproducibility test. The concentrations of the carbonyls are calculated values based on the amount injected into the simulation chamber. 
Simulation Chamber Experiments

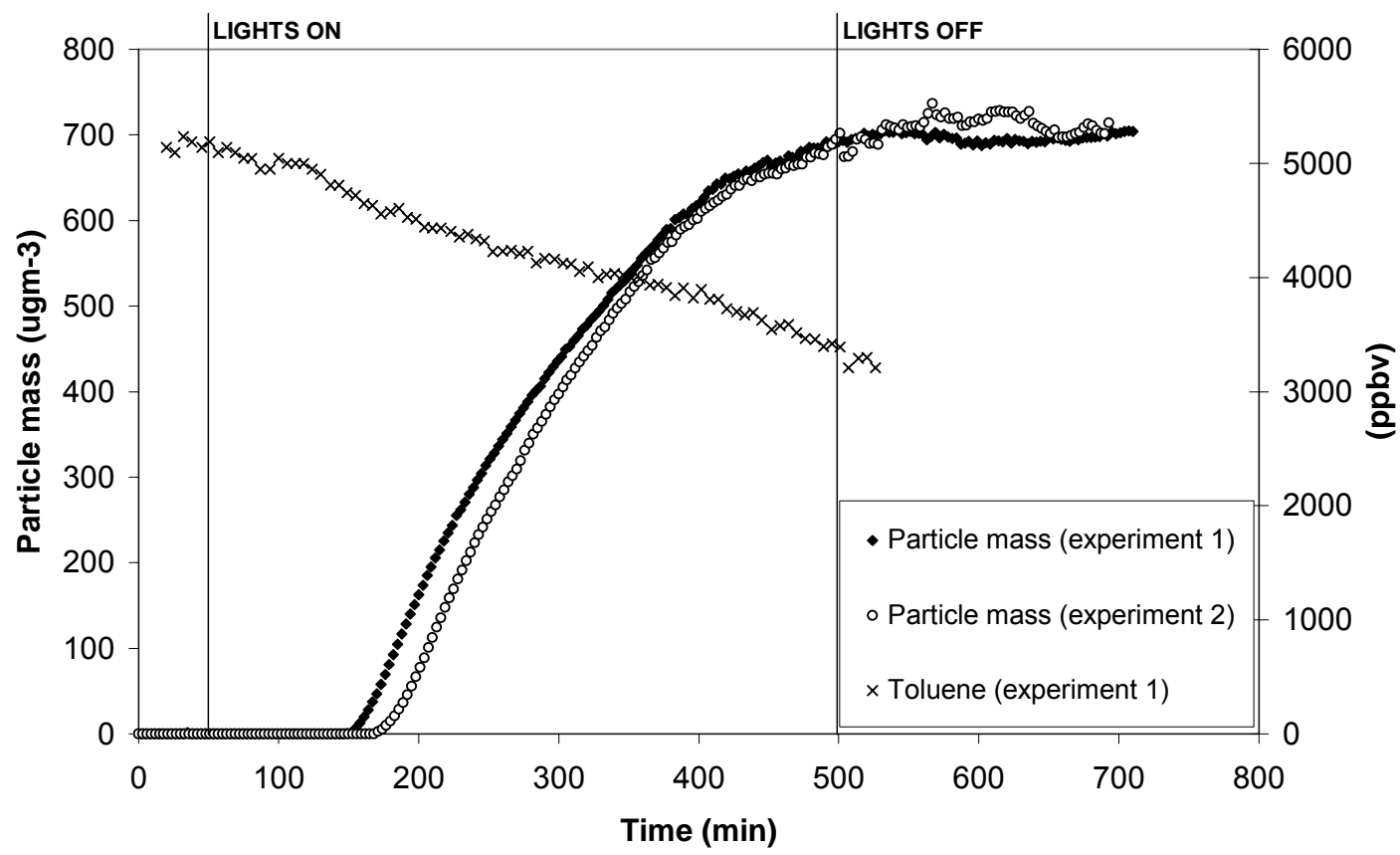

Figure S13. Particle mass concentration as a function of time for two replicate toluene photo-oxidation experiments (particle mass calculated assuming a density of $1.2 \mathrm{~g} \mathrm{~cm}^{-3}$ and corrected for wall loss). The toluene concentration for experiment 1 is also included. 


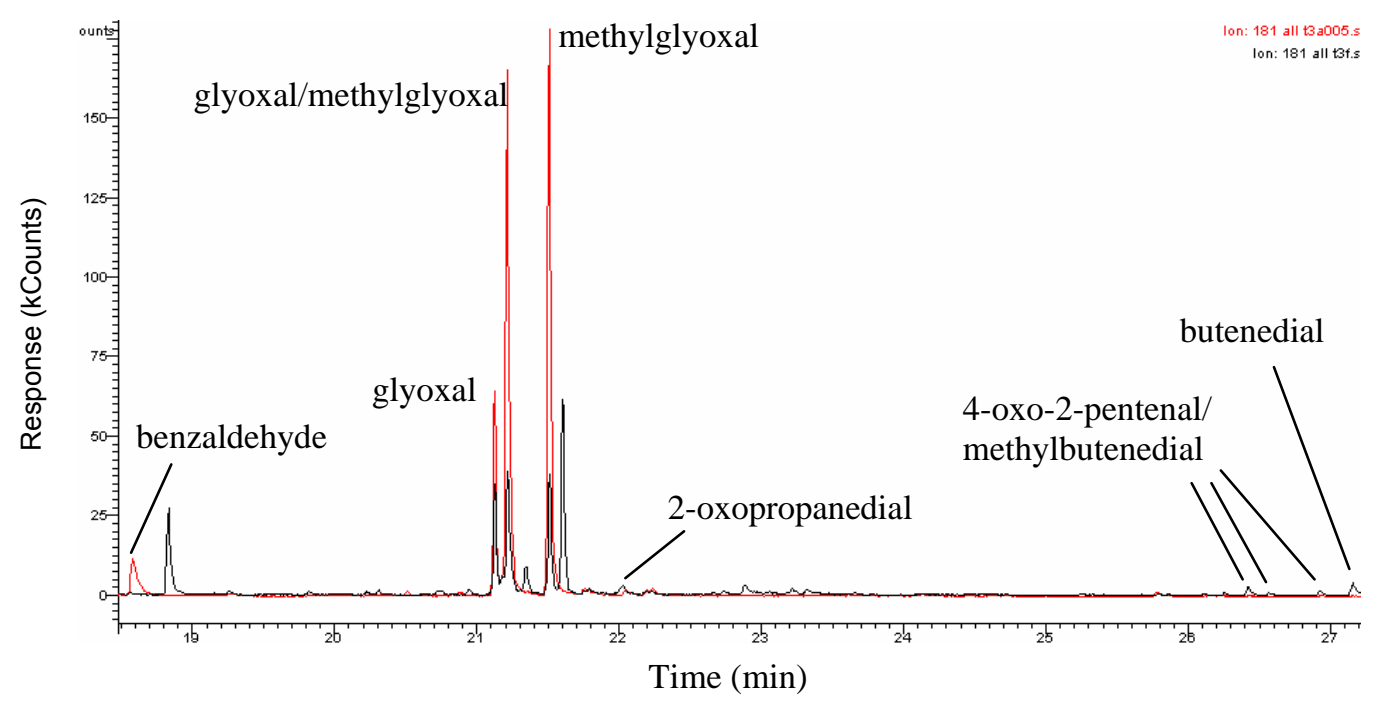

Figure S14. Reconstructed ion chromatogram $(\mathrm{m} / \mathrm{z} 181)$ of the carbonyl photooxidation products of toluene observed on the denuder (red) and filter (black) of the denuder-filter setup. It should be noted that the filter samples have been preconcentrated by a factor of 20 thus increasing their response when compared to the denuder extract. 


\begin{tabular}{|l|l|l|l|}
\hline Compound & $\begin{array}{l}\text { Retention time } \\
\text { (minutes) }\end{array}$ & $\begin{array}{l}\text { Molecular weight } \\
\text { of derivative }\end{array}$ & m/z (EI mode) \\
\hline Benzaldehyde & 18.57 & 301 & $\begin{array}{l}181 \\
301(\mathrm{M}) \\
271(\mathrm{M}-30)\end{array}$ \\
\hline Glyoxal & $21.13,21.22$ & 448 & $\begin{array}{l}181 \\
448(\mathrm{M}) \\
\end{array}$ \\
& & & $251(\mathrm{M}-197)$ \\
\hline Methylglyoxal & $21.24,21.51$ & 462 & 181 \\
& & & $462(\mathrm{M})$ \\
& & $4765(\mathrm{M}-197)$ \\
\hline 2-oxopropanedial & $22.19,22.23$ & & 181 \\
& & & $476(\mathrm{M})$ \\
& & 488 & 181 \\
& & $488(\mathrm{M})$ \\
\hline $\begin{array}{l}\text { Methylbutenedial/ } \\
\text { 4-oxo-2-pentenal }\end{array}$ & $25.80,25.86$, & 181 \\
\hline Butenedial & $26.25,26.43,26.94$ & & $474(\mathrm{M})$ \\
\hline
\end{tabular}

Table ST4. Particle phase products from the photo-oxidation of toluene identified by GC-MS. 